\title{
Desain Hunian Terapung di Jakarta Utara
}

\author{
Adelia Hanindya Nastiti dan Ima Defiana \\ Departemen Arsitektur, Fakultas Teknik Sipil dan Perencanaan, Institut Teknologi Sepuluh Nopember (ITS) \\ e-mail: may.d@arch.its.ac.id
}

\begin{abstract}
Abstrak-Pemanasan Global yang terjadi belakangan ini telah mengakibatkan bongkahan es yang ada di Antartika dan Greenland tersebut mulai mencair secara perlahan, dan hal ini berakibat adanya kenaikan muka air laut secara global. Jakarta Utara menjadi salah satu area di Indonesia yang mengalami dampak yang cukup signifikan akibat kenaikan muka air laut dan sebagian besar lahan yang tergenang adalah lahan yang diperuntukkan sebagai permukiman. Dalam rangka mengantisipasi permasalahan tersebut, upaya yang dapat dilakukan adalah perancangan kompleks hunian dengan menggunakan struktur terapung. Hunian terapung ini bertujuan untuk meminimalisir resiko kerusakan dari bidang properti secara signifikan saat sebagian daratan tenggelam akibat isu tersebut. Hunian dirancang dengan menggunakan prinsipprinsip dari Arsitektur Organik. Desain dari hunian ini dibuat dengan material konstruksi yang ringan, dan struktur stabil yang bisa menyesuaikan dengan permukaan air laut dan juga modifikasi model bangunan agar aman dari genangan air laut, terutama pada saat kondisi air pasang.
\end{abstract}

Kata Kunci-Arsitektur Organik, Kenaikan Muka Air Laut, Pemanasan Global.

\section{PENDAHULUAN}

$\mathrm{S}$ EIRING dengan meningkatnya temperatur air laut akibat pemanasan global, bongkahan es yang ada di Antartika dan Greenland tersebut mulai mencair secara perlahan, dan hal ini berakibat adanya kenaikan muka air laut secara global [1]. Mengingat kondisi geografis Indonesia yang berbentuk kepulauan yang luasan wilayahnya didominasi oleh lautan, maka terlihat bahwa negara ini sangat rentan terhadap berkurangnya daratan akibat kenaikan muka laut.

Jakarta Utara merupakan satu dari berbagai wilayah di Indonesia yang mengalami dampak terbesar akibat kenaikan muka air laut. Wilayah Jakarta Utara yang landai dan penggunaan lahan yang tidak memperhatikan daya lingkungan telah menyebabkan genangan akibat kenaikan muka air laut semakin ke arah daratan. Saat ini Jakarta telah mengalami kenaikan muka air laut sebanyak $1,8 \mathrm{~cm}$ per tahun dan juga penurunan muka tanah sebanyak $12 \mathrm{~cm}$ per tahun [2], dan menurut IPCC pada tahun 2030 diprediksi kenaikan muka air laut akan mencapai $6,45 \mathrm{~m} \mathrm{[3].}$

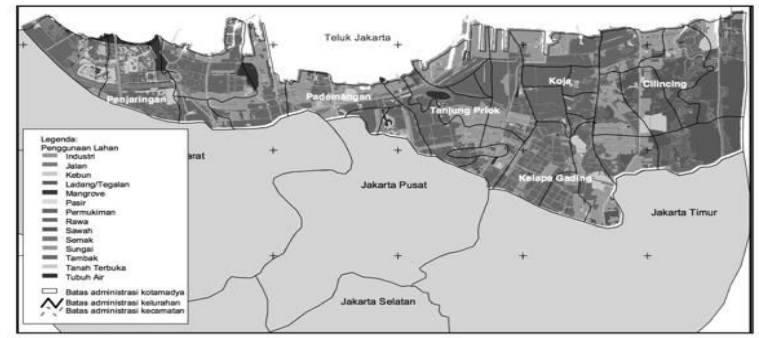

Gambar 1. Peta peruntukan lahan Jakarta Utara.

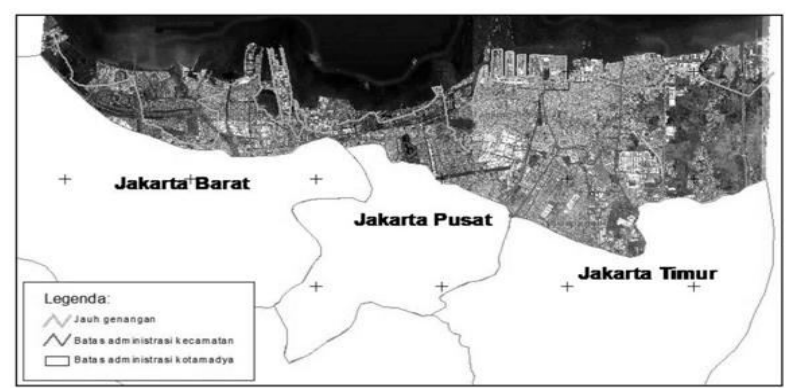

Gambar 2. Prediksi kenaikan muka air laut.

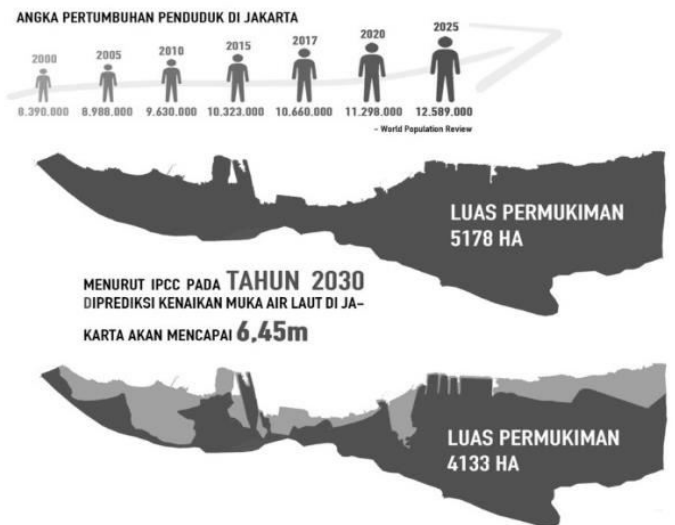

Gambar 3. Angka Pertumbuhan Penduduk Jakarta dan Prediksi Kenaikan Muka Air Laut.

Dengan berdasar pada data penggunaan lahan di Jakarta Utara (Gambar 1), maka dapat diprediksikan luas kerusakan lahan akibat adanya prediksi kenaikan muka air laut yang paling banyak tergenang adalah permukiman [4] (Gambar 2) dibandingkan dengan penggunaan lahan lainnya. Dilain sisi, Jakarta juga memiliki angka pertumbuhan penduduk yang terus mengalami peningkatan setiap tahunnya. Pada tahun 2000 jumlah penduduk Jakarta mencapai 8.390.000 jiwa, dan terus mengalami peningkatan yang relative konstan mendekati angka 7\% per tahun [5] (Gambar 3). Semakin meningkatnya jumlah penduduk pada kota Jakarta ini akan mengakibatkan semakin meningkatnya penggunaan lahan. Namun dengan adanya isu tentang kenaikan muka air laut yang beresiko menenggelamkan sebagian daratan di Jakarta, maka perlu adanya usaha untuk beradaptasi dengan keadaan tersebut yaitu dengan mengembangkan rancangan berupa hunian dengan menggunakan struktur terapung (Floating House) dengan skala yang tidak terlalu besar. Didesain semaksimal mungkin untuk bisa fleksibel menyesuaikan dengan permukaan air laut. Modifikasi model bangunan agar aman dari genangan air laut, terutama pada saat kondisi air pasang dan bertujuan untuk meminimalkan resiko kerusakan akibat kenaikan muka air laut. 


\section{METODA PERANCANGAN}

Area hunian beserta fasilitas pendukung dirancang menggunakan Pendekatan Ekologi yang menyelesaikan permasalahan arsitektur dengan mengutamakan keselarasan rancangan dengan alam, melalui pemecahan secara teknis dan ilmiah. Selain itu, desain area hunian ini juga menerapkan Metode yang berdasar kepada prinsip-prinsip Arsitektur Organik dari Frank Lloyd Wright [6] atau arsitektur yang secara visual dan lingkungan saling harmonis, terintegrasi dengan tapak, dan merefleksikan kepedulian arsitek terhadap proses dan bentuk alam yang diproduksinya. Prinsip-prinsip tersebut adalah [7]:

1) Building and Site

Arsitektur organik terintegrasi dengan baik dengan tapak dan memiliki sebuah kesatuan, komposisi yang saling berkaitan, sebagian bentukan bangunan diambil dari sifat-sifat atau karateristik dari lahan. Sehingga hubungan bangunan dan lahan ini akan menimbulkan hasil yang berbeda-beda di setiap tempat, sesuai dengan lingkungannya.

\section{2) Materials:}

Material yang digunakan dapat mengaplikasikan prinsipprinsip alam pada arsitektur. Prinsip alam tidak hanya pada prinsip yang mengarah pada prinsip keberlanjutan dan pada prinsip teknologi (struktur) yang dapat dipelajari dari organisme tertentu. Dalam penggunaan material ada kecenderungan tertentu dalam arsitektur organic, seperti: menggunakan material yang dapat memiliki beberapa fungsi sekaligus, jumlah material seminimal mungkin, dan jika mungkin, gunakan material bangunan yang tidak beracun dan desainnya dapat mengurangi polusi dalam bangunan.

3) Shelter

Bangunan harus bisa melindungi pengguna di dalamnya. Pengguna tidak boleh merasa kekurangan privasi, atau merasa ter-expose dan tidak terlindungi.

4) Space

Arsitektur organik mengharmonisasikan antara ruang luar dan ruang dalam. ruang dalam tidak perlu dikotak-kotakkan, melainkan mengalir bebas dari tempat satu ke tempat lain.

\section{5) Nature}

Pada arsitektur organik, bentuk, warna, pola, tekstur, proporsi, ritme, dan pertumbuhan semua mengacu pada alam. Bukan berarti sebagai imitasi terhadap alam, tetapi berkaitan dengan material alami, lahan, dan orang-orang yang akan menempati bangunan.

\section{6) Grammar}

Setiap bangunan memiliki 'tatabahasa' sendiri, kosa kata yang berbeda dari pola dan bentuk. Semua bagian dari bangunan dari detail terkecil ke bentuk keseluruhan 'berbicara' bahasa yang sama.

\section{7) Simplicity}

Arsitektur organik tergolong sederhana karena skema dan desain yang jelas. Rancangan ini adalah sebuah perpaduan antara wilayah darat dan laut yang dirancang membentuk kompleks bangunan residensial yang bersifat privat. (Gambar 4 dan Gambar 5) Pada bagian laut terdapat kompleks hunian yang terdiri dari 3 tipe dan masing-masing dibedakan berdasarkan dimensi, dan kapasitas pengguna, dan pada bagian darat terdapat beberapa fasilitas penunjang. Kompleks hunian ini dihubungkan menuju ke daratan oleh jalur penghubung yang berfungsi sebagai jalur utama menuju masing - masing hunian berbentuk dermaga fixed yang didesain dengan pola linier terbuka ke laut.

Dalam desain nya area hunian ini menerapkan salah satu prinsip arsitektur organik yaitu 'grammar' yang membahas tentang unity atau kesatuan, bagaimana membuat keseluruhan desain bangunan 'berbicara' bahasa yang sama. (Gambar 6) Hal ini berusaha dicapai melalui keseragaman material yang digunakan, dan sifat bentuk dasar bangunan yaitu lingkaran. Bentukan lingkaran diambil karena menyesuaikan dengan bentukan lambung/konstruksi penampang hunian dibuat dengan bentuk silindris, (Gambar 8) sehingga memungkinkan penampang memiliki ketahanan hidrodinamis yang sama untuk segala arah pada saat terkena gelombang dan dapat menjadi lebih stabil.

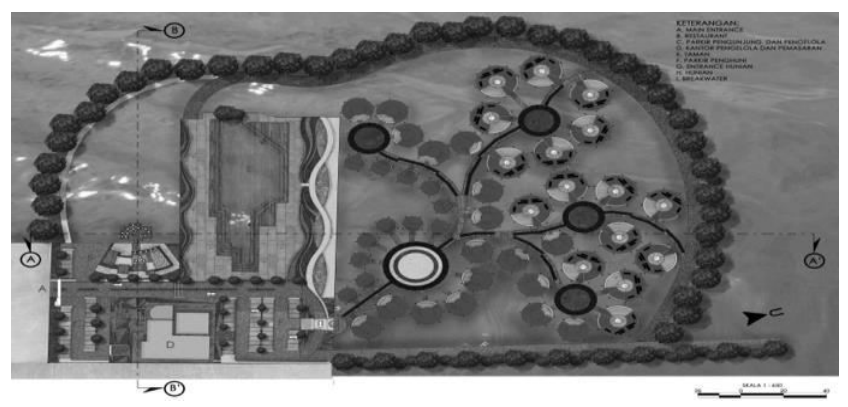

Gambar 4. Site Plan.
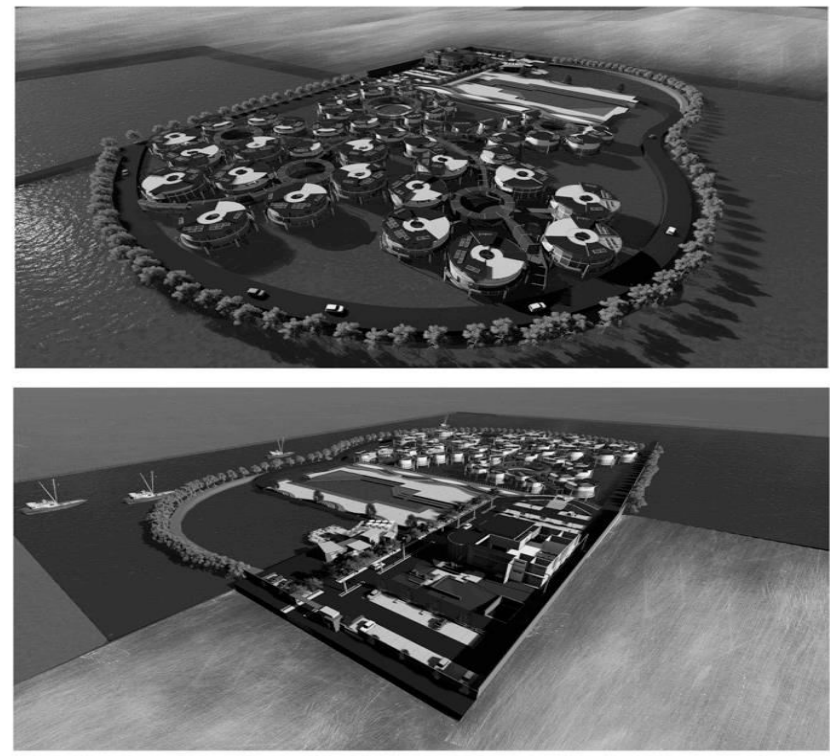

Gambar 5. Aerial View.

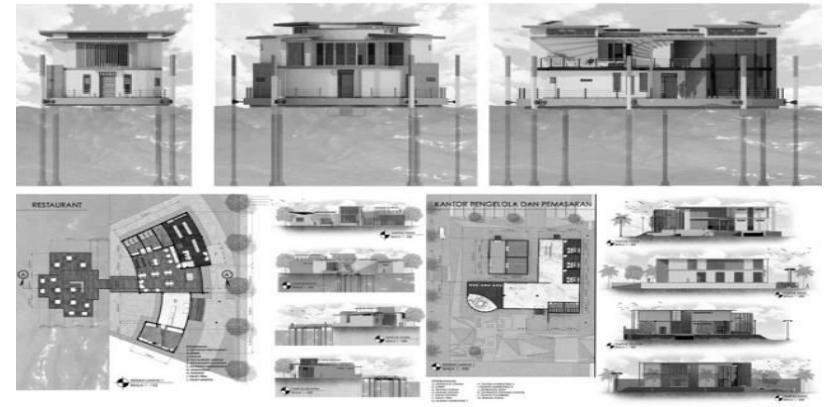

Gambar 6. Tampak. 

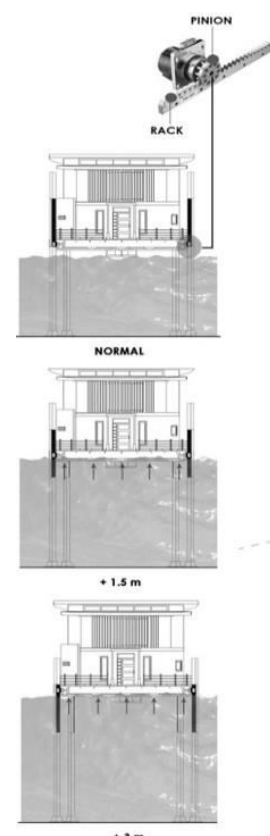

Gambar 7. Ilustrasi Saat Terjadi Kenaikan Air Laut.

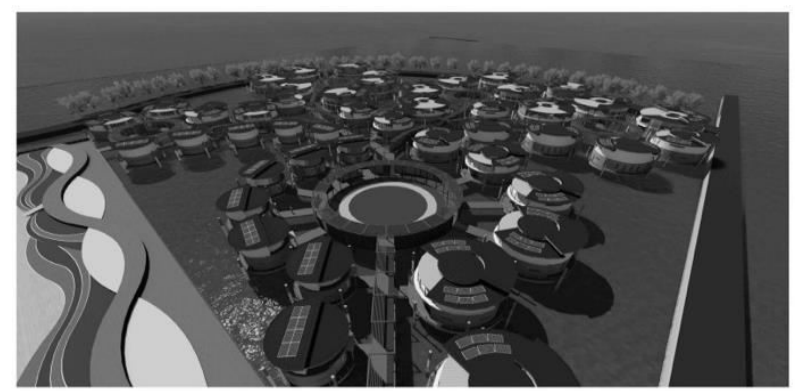

Gambar 8. Aerial View.

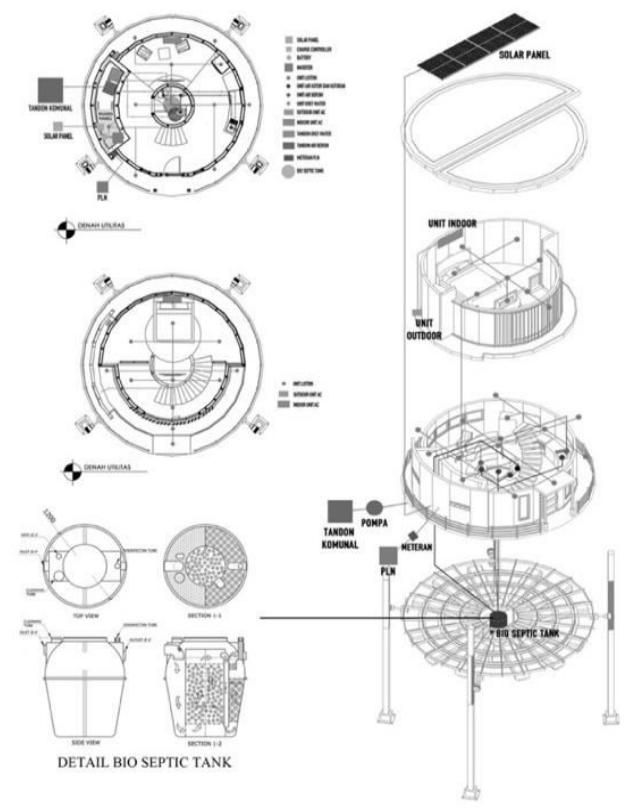

Gambar 9. Utilitas Hunian.
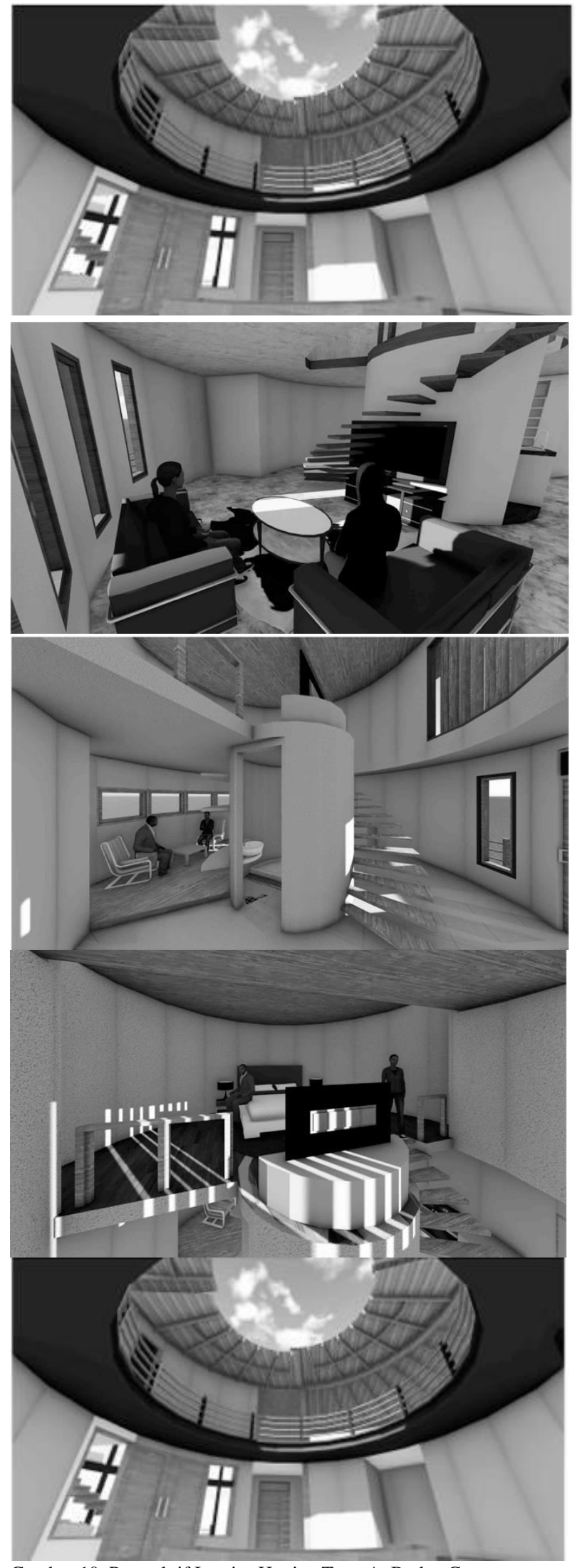

Gambar 10. Perspektif Interior Hunian Type A, B, dan C. 


\section{HASIL DAN EKSPLORASI}

Konstruksi bagian bawah hunian terapung dirancang untuk dapat fleksibel mengikuti pergerakan permukaan air (Gambar 7), dengan menggunakan prinsip sistem Rack and Pinion dan bantuan dari Buoyancy Billets. Pada hunian terapung ini, pergerakan air keatas digunakan sebagai gaya dorong hunian, agar saat level air laut naik, hunian dapat naik mengikuti pergerakan level air laut tersebut. Rack and Pinion berfungsi untuk menjaga pergerakan hunian tetap linier, gaya yang diterapkan pada pinion menyebabkan pinion menyebabkan pinion bergerak relatif terhadap rack, sehingga dapat mengarahkan gerak rotasi pinion ke dalam gerakan linier. Buoyancy Billets berfungsi untuk daya apung sehingga dapat mencegah hunian tenggelam saat adanya kenaikan level air laut.

Ruang dalam pada hunian terapung ini akan dirancang sesuai dengan metode arsitektur organik, yaitu dalam perancangan ruang adalah ruang yang bebas mengalir sehingga terjadi kesatuan antara alam, ruang luar hingga ke ruang dalam. (Gambar 10) Konsep tersebut menghasilkan ruang yang bersifat fleksibel, dinamis dan luas. Konsep kedekatan ruang dalam dengan lingkungan dicapai dengan ruang yang terbuka, bukaan yang lebar dan penggunaan material transparan, sehingga menciptakan kesatuan baik secara visual, penghawaan maupun pencahayaan.

Masing-masing unit hunian dilengkapi dengan sistem utilitas (Gambar 9) berupa distribusi air bersih, pengelolan air kotor dan kotoran, elektrikal, dan penghawaan. Distribusi air bersih disalurkan dari PDAM menuju ke tendon komunal yang ada di titik-titik yang sudah ditentukan pada bagian bawah jalur sirkulasi yang kemudian dipompa menuju ke tendon masing-masing unit hunian. Pengelolaan air kotor dan kotoran terdapat pada masing-masing unit dengan memanfaatkan Bio
Septic Tank, nantinya limbah dari hunian ini akan diolah dan hasil dari olahan berupa grey water akan disalurkan menuju tendon grey water dan dimanfaatkan sebagai keperluan flushing.

\section{KESIMPULAN/RINGKASAN}

Perubahan iklim yang berakibat pada kenaikan permukaan air laut, sudah dapat kita rasakan kurun waktu dekat, namun efek yang sebenarnya akan baru bisa terukur dalam beberapa dekade. Ini adalah kerangka waktu di mana perencanaan, perancangan dan pengembangan harus mulai dilakukan. Indonesia merupakan negara yang luasannya wilayahnya didominasi oleh perairan, karena itu pembangunan berbasis kearah laut merupakan solusi terbaik yang harus dipertimbangkan. Perairan di Indonesia dapat dimanfaatkan agar menjadi zona yang produktif yaitu sebagai tempat bermukim masyarakat modern. Karena untuk mempersiapkan masa depan, kita tidak harus melihat keterbatasan yang ada, namun pada kesempatan yang dihadirkannya.

\section{DAFTAR PUSTAKA}

[1] Anonymous, "No Title." [Online]. Available: http://earthobservatory.nasa.gov.

[2] Anonymous, "No Title." [Online]. Available: http://pressreader.com.

[3] IPCC, "Intergovernmental Panel and Climate Change." .

[4] N. Anggraini, "Application of Sattelite Data to Analyze Innudation Potential and the Impact of Sea Level Rise," Universitas Indonesia, 2012.

[5] Anonymous, "No Title." [Online]. Available: http://worldpopulationreview.com.

[6] E. Kaufman and B. Raeburn, Frank Lloyd Wright: Writings and Buildings. 1969.

[7] Anonymous, "No Title." [Online]. Available: http://flwright.org/ckfinder/userfiles/files/Wright-OrganicArchitecture.pdf. 